ERRATUM

\title{
Erratum to: Leaf trait plasticity in six forest tree species of central Amazonia
}

\author{
R.A. MARENCO ${ }^{*,+}$, M.A.B. CAMARGO ${ }^{* *}$, S.A. ANTEZANA-VERA ${ }^{* *}$, and M.F. OLIVEIRA ${ }^{* *}$ \\ Coordination of Environmental Dynamic, National Institute for Research in the Amazon (INPA), Avenida \\ André Araújo, 2936, 69067-375, Manaus - AM, Brazil \\ INPA's Botany Graduate Program, Avenida André Araújo, 2936, 69067-375, Manaus - AM, Brazil ${ }^{* *}$
}

Erratum to: Photosynthetica

DOI: 10.1007/s11099-017-0703-6

The heading in Table 2 was corrected to $\mathrm{D}_{\mathrm{s}}\left[\mathrm{mm}^{-2}\right]$ (see the next page)

The publisher and authors apologize for these errors and for inconveniences they may have caused.

The online version of the original article can be found under doi: 10.1007/s11099-017-0703-6

${ }^{+}$Corresponding author; phone: 55923643 1841, e-mail: $\underline{\text { rmarenco@inpa.gov.br }}$ 


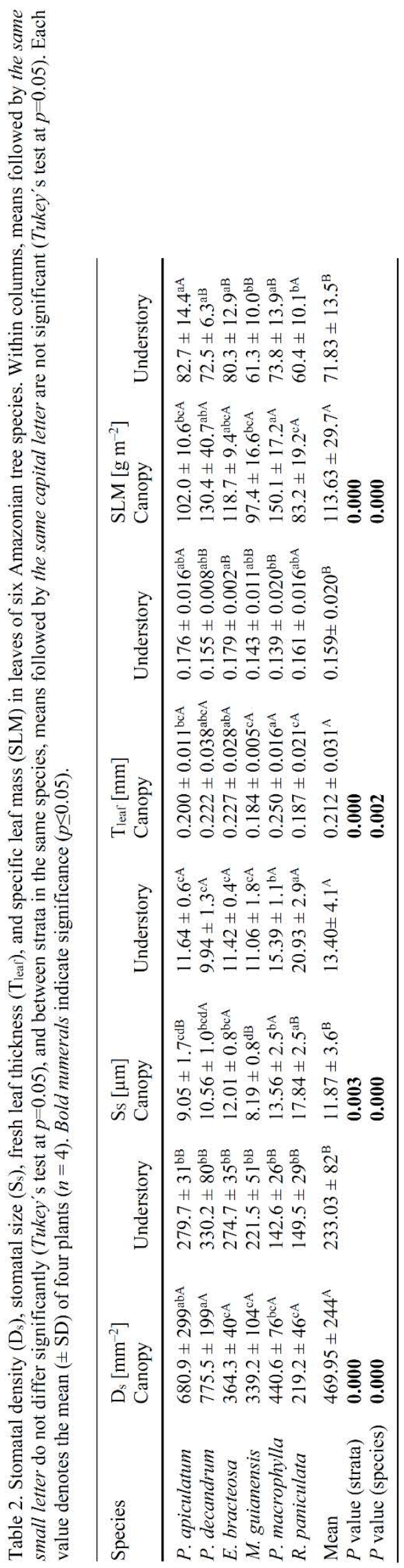

